\title{
Association of Overall Screen Time and Outdoor Activity with Emotional and Behavioral Health Problems
}

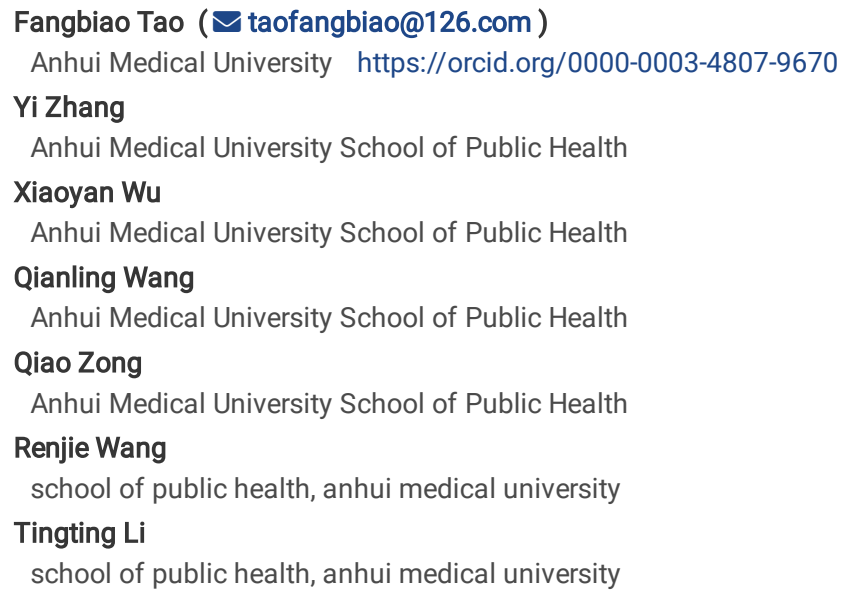




\section{Abstract}

Background

Psychological problems among children and adolescents have become a public health issue. This study aimed to investigate associations between screen time (ST), outdoor activity (OA), and emotional and behavioral health problems (EBHPs) among South Chinese children and adolescents.

\section{Methods}

A total of 30,188 boys and girls from 14 elementary and junior high schools on six streets in Shenzhen were included in this study. EBHPs were measured with the strengths and difficulties questionnaire; OA and ST data were obtained through self-reporting. Descriptive analyses, chi-square tests, and logistic regressions were performed using SPSS 23.0.

\section{Results}

In our study, $42.4 \%$ students had insufficient OA, $24.2 \%$ students had excessive ST, the abnormal prevalence of emotional symptoms, conduct problems, peer problems, hyperactivity problems, prosocial behavior, and total difficulties scales were $18.5 \%, 6.9 \%, 6.4 \%, 13.1 \%, 10.7 \%$ and $8.8 \%$. There were significant associations between ST/OA, independent and addictive interaction, and EBHPs among children and adolescents. Participants with high exposure to ST were more likely to have EBHPs than those with low exposure; participants with low exposure to OA were also more likely to have EBHPs than those with high exposure. The interactive associations of ST and OA on EBHPs were stronger than those of ST or OA individually.

\section{Conclusions}

Our results show positive associations between ST, OA, and EBHPs. They indicate that interventions should be considered for decreasing ST and increasing $\mathrm{OA}$ in children and adolescents.

\section{Background}

Mental health problems which including depressive and anxiety symptoms or disorders, or attention deficit hyperactivity and behavior disorder (ADHD), can have a serious impact on the current and future health and well-being of adolescents, in many ways, this causes a public health crisis. [1,2]. About 10-20\% of children and adolescents are affected by psychological health problems worldwide [3]

Children's leisure activities primarily include watching television and using digital entertainment devices, especially games and live shows on mobile phones or tablets, and these have become major features of home environments in many countries. However, higher levels of screen time (ST) in children have been linked to obesity, sleep problems, lower cognitive skill, and poor academic record [4-6]. High exposure to ST may also predict behavioral and emotional problems in children, including aggression [7,8], anxiety and depression [8,9], social isolation [10], reduced prosocial behavior [7,11] and attentional problems [7,12-13]. We have also learned that the association between high ST and mental health outcomes among children and adolescents. Some studies have found positive correlations between high ST and ADHD [14-16-]. ST also reduces time spent on other major developmental activities, including networking and interpersonal interaction [17]. It is thought that many psychological processes associated with exposure to TV and tablets, phones, games, or videos are similar, particularly those regarding the development of attentional problems and aggressive behavior [18]. A recent study found negative effects of television and video game exposure on attentional problems in middle childhood [13]. In one study, gaming's interactive and absorbing qualities may have substituted for interpersonal relationships and thus increased social isolation [19]. Social isolation also causes negative emotional influence [20]. A longitudinal study demonstrated that watching TV for three hours or more at 5 years of age, compared to watching TV for under one hour, predicted a 0.13 point increase in conduct problems by age 7 [21].

In some longitudinal and interventional studies, maintaining regular physical activity (PA) has been inversely associated with psychosocial difficulties in adolescents [22-23]. Researchers found that regular PA can reduce negative emotional symptoms [22,23]. Moreover, according to a survey of a large proportion of adolescents, in many countries, adolescents do not yet met the World Health Organization's recommendation for daily PA [24]. Therefore, it is necessary to strengthen commitment to PA in children and adolescents. One longitudinal study discussed the association between PA and emotional problems after one year in a cohort of school children, finding that children who met the recommended levels for PA had fewer emotional problems [25]. Additionally, the combination of taking time outdoors and participating in physical activity can improve mental health [26]. There is also growing evidence that more outdoor activity (OA) time is associated with increased positive mental health in adults [27]. The same study also described in a population-based sample of adults that increased time spent outdoors is linked to fewer depression symptoms [28]. In a similar way, a nationally representative study of Canadian children, every hour spent outdoors per day was associated with a one third reduction in the odds of reporting peer relationship problems and a lower odds of reporting psychosocial difficulties [29]. What's more, outdoor time can increase OA [29]. Moreover, increasing OA is associated with decreasing anxiety and depression and also improvement of mental health [30]. In a Canadian adolescents study, girls spending on average $>0.5 \mathrm{~h} /$ week outdoors was associated with a lower prevalence of high psychosomatic symptoms, compared to those who averaged no time playing outdoors [31].

Previous studies have found associations between ST and and PA in mental and emotional health [32-34]. The combination of high ST and insufficient PA is associated with a higher prevalence of various psychological problems [32]. However, few studies have considered the interaction of OA and ST on emotional and behavioral health problems (EBHPs) among children and adolescents. In recent years, with the development of electric media, adolescents spending time on these, their time on exercise, especially outdoor activity showed a declined trend [35,36]. High levels of physical inactivity and sedentary behavior are a global concern, add to that the importance of mental health. Therefore, the present study aims to assess individual and interactive associations between OA, 
ST, and EBHPs among Chinese children and adolescents in order to provide a better theoretical basis for explaining EBHPs through the interaction of ST and OA.

\section{Methods}

\subsection{Study sample}

The questionnaire on the growth trajectory and health index of primary and secondary school students was a prospective survey representing physical and psychological problems of contemporary children and adolescents. Ultimately, 14 schools were selected in Shenzhen, Bao'an district. In total, 33,801 children and adolescents in grades 1-12 were withdrawn as those that did not meet the requirements or had incomplete data were removed, so that 30,188 children and adolescents were selected. The age range was 6 to 18 years. Written informed consent and questionnaires were obtained from the students or their parents. There were two types of questionnaires: one for parents (grades 1-4) and one for self-reporting (grades 5-12). This study was approved by the Ethics Committee of Anhui Medical University.

\subsection{Screen time}

The ST of participants was determined with two questions. One question was, "How much time do you / your child spend watching TV, using computers, and playing with cell phones or other electric devices on an average weekday?" The other was, "How much time do you /your child spend watching TV, using computers, and playing with cell phones or other electric devices on an average weekend day?" The overall average ST was calculated according to previous methods [37]. ST was categorized as $\geq 2 \mathrm{~h} /$ day (high) or $₫ 2 \mathrm{~h} /$ days (low) [38].

\subsection{Outdoor activity}

The OA option had two questions, which were, "On an average weekday (Monday to Friday) during the past month, how much time did you usually spend time on outdoor activity?" and "On an average weekend day (Saturday or Sunday) during the past month, how much time did you usually spend time on outdoor activity?" Minutes spent outdoors per week were computed as [( $5 *$ outdoor time on weekdays $)+(2 *$ outdoor time on weekend days)], to convert this estimate to hours per day, we divided the estimate by 420 (60 $\mathrm{min} * 7$ days per week) [26]. OA was categorized as $\otimes 1 \mathrm{~h} /$ day and $\geq 1 \mathrm{~h} / \mathrm{day}$ [26].

\subsection{Emotional and behavioral health problems}

Participants self-reported using the strengths and difficulties questionnaire (SDQ) [39]. The 25 items of the SDQ are used to measure strengths and difficulties on five scales (emotional symptoms, conduct problems, hyperactivity problems, peer problems, and prosocial behavior). Each scale contains five items scored from 0 to 2, giving a scale range of 0 to 10. The score for total difficulties is the sum of four scales (prosocial behavior is excluded). Higher scores reflect greater difficulty (excluding prosocial behavior). SDQ scores (including total difficulties, prosocial behavior, emotional symptoms, conduct problems, hyperactivity problems, and peer problems) were categorized as normal, borderline, or abnormal. Total SDQ scores above the 90 th percentile were classified as abnormal; those in the 80th to 90th percentile range were 'borderline,' and those below the 80th percentile were 'normal' [40]. Children's responses were categorized as normal, borderline, or abnormal for each subscale.

\subsection{Covariates}

In this analysis, demographic information was included as covariates, such as sex, family economic level, parental education, academic record, and homeplace. Family economic level was classified as below moderate, moderate, or above moderate. Parental education level was classified as junior high or below, senior high, or junior college and above. Academic record was classified as below moderate, moderate, or above moderate. Homeplace was classified as country, city, or town.

\subsection{Statistical analyses}

Statistical analyses were performed with SPSS 23.0. Descriptive analyses were used to show demographic information of the sample. Pearson's chi-squared tests were performed to test the prevalence of EBHPs. Andersson Excel was used to calculate the interaction data of the additive interaction model [41]. Multivariable logistic regression was used to explore the independent and interactive associations of ST and OA. A p $<0.05$ was considered significant.

\section{Results}

\subsection{Participant characteristics}

Demographic information of the participants are shown in Table 1. Participants included 16,897 boys (56.0\%) and 13,291 girls (44.0\%). According to the selfreport, more than half $(77.1 \%)$ spent less than two hours per day on ST and more than half $(57.6 \%)$ of children and adolescents spending more time on outdoor activity. In out study, the abnormal of emotional symptoms, conduct problems, peer problems, hyperactivity problems, prosocial behavior, and total difficulties scales were $18.5 \%, 6.9 \%, 6.4 \%, 13.1 \%, 10.7 \%$ and $8.8 \%$. Other variables are shown in Table 1 .

Table 1 Demographic information 


\begin{tabular}{|c|c|c|}
\hline variables & & $\mathrm{n}(\mathbb{\nabla})$ \\
\hline \multirow[t]{2}{*}{ Gender } & girl & $13291(44.0)$ \\
\hline & boy & 16897(56.0) \\
\hline \multirow[t]{2}{*}{ Age } & $\leq 12 y$ & $14484(48.0)$ \\
\hline & Q12y & 15704(52.0) \\
\hline \multirow[t]{3}{*}{ Grade } & primary & $13420(44.5)$ \\
\hline & junior & 8232(27.3) \\
\hline & senior & 8536(28.3) \\
\hline \multirow[t]{3}{*}{ Academic record } & good & $7580(25.1)$ \\
\hline & medium & $17573(58.2)$ \\
\hline & bad & $5035(16.7)$ \\
\hline \multirow[t]{3}{*}{ Residential area } & country & $5585(18.5)$ \\
\hline & town & 2754(9.1) \\
\hline & city & $21838(72.4)$ \\
\hline \multirow[t]{3}{*}{ Father education } & junior high or lower & 9461(31.9) \\
\hline & senior high & 11387(37.7) \\
\hline & junior college or above & $9160(30.3)$ \\
\hline \multirow[t]{3}{*}{ Mother education } & junior high or lower & $12203(40.5)$ \\
\hline & senior high & 11184(37.0) \\
\hline & junior college or above & $6801(22.5)$ \\
\hline \multirow[t]{3}{*}{ Family economic } & under moderate & $4113(13.6)$ \\
\hline & moderate & 20395(67.6) \\
\hline & over moderate & $5680(18.8)$ \\
\hline \multirow[t]{2}{*}{ Screen time } & $\leq 2 \mathrm{~h}$ & 23261(77.1) \\
\hline & $\nabla 2 \mathrm{~h}$ & 6921(22.9) \\
\hline \multirow[t]{2}{*}{ Outdoor activity } & $\nabla 1 \mathrm{~h}$ & $12797(42.4)$ \\
\hline & $\geq 1 \mathrm{~h}$ & 17391(57.6) \\
\hline
\end{tabular}

\subsection{Distribution of emotional and behavioral health problems}

Table 2 shows the distribution of EBHPs. Significant differences were found by father's education, academic record, and residential area in the distribution of emotional symptoms (father's education: $\chi^{2}=18.13, p<0.001$; academic record: $\chi^{2}=498.85, p<0.001$; residential area: $\chi^{2}=156.52, p<0.001$ ), conduct problems (father's education: $\chi^{2}=6.58, p<0.05$; academic record: $\chi^{2}=296.04, p<0.001$; residential area: $\chi^{2}=156.52, p<0.001$ ), peer problems (father's education: $\chi^{2}=12.12, p<0.01$; academic record: $\chi^{2}=217.16, p<0.001$; residential area: $\chi^{2}=14.36, p<0.001$ ), hyperactivity problems (father's education: $\chi^{2}=$ 12.09, $p<0.05$; academic record: $\chi^{2}=983.1, p<0.001$; residential area: $\chi^{2}=305.3, p<0.001$ ), prosocial behavior (father's education: $\chi^{2}=2.76, p>0.05$; academic record: $\chi^{2}=640.24, p<0.001$; residential area : $\chi^{2}=231.23, p<0.001$ ), and total difficulties (father's education: $\chi^{2}=23.08, p<0.001$; academic record: $\chi^{2}=550.96, p<0.001$; residential area: $\left.\chi^{2}=31.82, p<0.001\right)$. In addition, differences in family economic level were reflected in conduct problems $\left(\chi^{2}=\right.$ $40.57, p<0.001)$, peer problems $\left(\chi^{2}=30.86, p<0.001\right)$, hyperactivity problems $\left(\chi^{2}=367.57, p<0.001\right)$, prosocial behavior $\left(\chi^{2}=60.06, p<0.001\right)$, and total difficulties $\left(\chi^{2}=23.08, p<0.001\right)$, except for emotional symptoms. Moreover, effects of mother's education were not found for hyperactivity problems and conduct problems but were correlated with the other scales, while father's education showed a weak correlation with conduct problems, also no correlation with hyperactivity problems. Sex was found to affect emotional symptoms $\left(\chi^{2}=325.21, p<0.001\right)$, conduct problems $\left(\chi^{2}=138.61, p<0.001\right)$, peer problems $\left(X^{2}=144.41, p<0.001\right)$, hyperactivity problems $\left(\chi^{2}=89.34, p<0.001\right)$, and prosocial behavior $\left(\chi^{2}=197.7, p<0.001\right)$, but not total difficulties.

Table 2 Distribution of emotional and behavioral health problems 


\begin{tabular}{|c|c|c|c|c|c|c|c|c|c|c|c|}
\hline & \multicolumn{2}{|c|}{ emotional symptoms } & \multicolumn{2}{|c|}{ conduct problems } & \multicolumn{2}{|c|}{ hyperactivity problems } & \multicolumn{2}{|c|}{ peer problems } & \multicolumn{2}{|c|}{ prosocial behavior } & \multirow{2}{*}{$\begin{array}{l}\text { Total diffic } \\
N(\mathbb{(})\end{array}$} \\
\hline & $N(\mathbb{Z})$ & $x^{2}$ & $N(\mathbb{(})$ & $x^{2}$ & 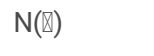 & $x^{2}$ & $N(\mathbb{\nabla})$ & $x^{2}$ & 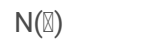 & $x^{2}$ & \\
\hline \multicolumn{12}{|l|}{ Gender } \\
\hline Boy & $2567(15.2)$ & $279.17^{\star \star \star}$ & 1375(8.1) & $89.9^{\star \star \star}$ & $2446(14.5)$ & $89.34^{\star \star \star}$ & $1209(7.2)$ & & $2125(12.6)$ & $141.99^{* k *}$ & $1429(8.5)$ \\
\hline Girl & $3019(22.7)$ & & $711(5.3)$ & & $1494(11.2)$ & & $726(5.5)$ & $35.54^{\star \star \star}$ & 1104(8.3) & & 1216(9.1) \\
\hline \multicolumn{12}{|l|}{ Age } \\
\hline$\leq 12 y$ & 1895(13.1) & $542.51^{\star \star *}$ & $947(6.5)$ & $5.98^{\star}$ & $2287(15.8)$ & $183.97^{* \star *}$ & $914(6.3)$ & 0.46 & $1596(11.0)$ & 3.04 & $1051(7.3)$ \\
\hline$\triangle 12 y$ & $3691(23.5)$ & & 1139(7.3) & & $1653(10.5)$ & & 1021(6.5) & & 1633(10.4) & & $1594(10.2)$ \\
\hline \multicolumn{12}{|l|}{ Grade } \\
\hline primary & $1644(12.3)$ & $640.64^{\star \star \star}$ & $809(6.0)$ & $108.39^{\star \star *}$ & $2160(16.1)$ & $218.22^{* \star *}$ & $797(5.9)$ & $33.96^{* \star *}$ & $1487(11.1)$ & $27.34^{\star \star \star}$ & $891(6.6)$ \\
\hline junior & $1841(22.4)$ & & $773(9.4)$ & & $774(9.4)$ & & $638(7.8)$ & & $758(9.2)$ & & $916(11.1)$ \\
\hline senior & 2101(24.6) & & $504(5.9)$ & & 1006(11.8) & & $500(5.9)$ & & $984(11.5)$ & & 838(9.8) \\
\hline \multicolumn{12}{|c|}{ Father education } \\
\hline $\begin{array}{l}\text { Junior } \\
\text { high or } \\
\text { lower }\end{array}$ & 1906(19.8) & $18.13^{* * *}$ & $702(7.3)$ & $6.58^{*}$ & $1298(13.5)$ & 2.76 & $687(7.1)$ & $12.12^{* *}$ & 1104(11.5) & $8.45^{*}$ & $942(9.8)$ \\
\hline $\begin{array}{l}\text { Senior } \\
\text { high }\end{array}$ & 2088(18.3) & & $801(7.0)$ & & $1445(12.7)$ & & $694(6.1)$ & & 1177(10.3) & & $989(8.7)$ \\
\hline $\begin{array}{l}\text { junior } \\
\text { college } \\
\text { or above }\end{array}$ & 1592(17.4) & & $583(6.4)$ & & 1197(13.1) & & $554(6.0)$ & & $948(10.3)$ & & $714(7.8)$ \\
\hline \multicolumn{12}{|c|}{ Mother education } \\
\hline $\begin{array}{l}\text { Junior } \\
\text { high or } \\
\text { lower }\end{array}$ & 2414(19.8) & $27.55^{\star \star \star}$ & $849(7.0)$ & 0.71 & $1621(13.3)$ & 2.28 & $859(7.0)$ & $15.09^{* *}$ & 1384(11.3) & $8.93^{*}$ & $1147(9.4)$ \\
\hline $\begin{array}{l}\text { Senior } \\
\text { high }\end{array}$ & 2031(18.2) & & $769(6.9)$ & & $1417(12.7)$ & & $689(6.2)$ & & $1149(10.3)$ & & $954(8.5)$ \\
\hline $\begin{array}{l}\text { Junior } \\
\text { college } \\
\text { or above }\end{array}$ & $1141(16.8)$ & & $468(6.9)$ & & 902(13.3) & & $387(5.7)$ & & $696(10.2)$ & & $544(8.0)$ \\
\hline \multicolumn{12}{|c|}{ Academic record } \\
\hline Good & 1003(13.2) & $498.85^{\star \star \star}$ & $359(4.7)$ & $269.04^{\star \star \star}$ & $522(6.9)$ & $640.24^{\star \star \star}$ & $326(4.3)$ & $217.16^{\star \star \star}$ & $586(7.7)$ & $162.8^{\star \star \star}$ & $395(5.2)$ \\
\hline Medium & 3133(17.8) & & $1121(6.4)$ & & $2291(13.0)$ & & $1068(6.1)$ & & 1893(10.8) & & 1399(8.0) \\
\hline Bad & $1450(28.8)$ & & $606(12.0)$ & & $1127(22.4)$ & & $541(10.7)$ & & $750(17.9)$ & & $851(16.9)$ \\
\hline \multicolumn{12}{|c|}{ Residential areas } \\
\hline City & $4378(20.0)$ & $156.52^{* \star *}$ & $1589(7.3)$ & $24.28^{* \star *}$ & $2487(11.4)$ & $231.23^{\star \star \star}$ & $1461(6.7)$ & $14.36^{* \star *}$ & $2223(10.2)$ & $27.53^{* * \star}$ & 2023(9.3) \\
\hline Country & $714(12.8)$ & & $302(5.4)$ & & $1062(19.0)$ & & $296(5.3)$ & & $704(12.6)$ & & $384(6.9)$ \\
\hline Town & $491(17.8)$ & & 195(7.1) & & $390(14.2)$ & & $175(6.4)$ & & $300(10.9)$ & & $237(8.6)$ \\
\hline \multicolumn{12}{|c|}{ Family economic level } \\
\hline $\begin{array}{l}\text { Under } \\
\text { moderate }\end{array}$ & $813(19.8)$ & 5.63 & $303(7.4)$ & $40.57^{\star \star \star}$ & 894(21.7) & $367.57^{\star \star \star}$ & $320(7.8)$ & $30.86^{* * *}$ & $577(14.0)$ & $60.06^{* \star *}$ & $470(11.4)$ \\
\hline Moderate & $3745(18.4)$ & & $1289(6.3)$ & & $2543(12.5)$ & & 1198(5.9) & & $2119(10.4)$ & & 1665(8.2) \\
\hline $\begin{array}{l}\text { Over } \\
\text { moderate }\end{array}$ & $1028(18.1)$ & & $494(8.7)$ & & $503(8.9)$ & & $417(7.3)$ & & 533(9.4) & & $510(9.0)$ \\
\hline
\end{tabular}

\subsection{Independent effects of screen time and outdoor activity on emotional and behavioral health problems}

After adjusting for gender, father's and mother's education, family economic level, residential area, and academic record, Table 3 shows the independent effects of ST and OA on MBHPs. There were positive relationships between ST, OA, and EBHPs. Higher ST caused more emotional symptoms (OR = 1.47; 95\% Cl: $1.37-1.57, p<0.001)$, conduct problems (OR $=1.63 ; 95 \% \mathrm{Cl}: 1.24-1.47, \mathrm{p}<0.001)$, peer problems $(\mathrm{OR}=1.26 ; 95 \% \mathrm{Cl}: 1.19-1.34, \mathrm{p}<0.001)$, hyperactivity problems $(\mathrm{OR}=1.35 ; 95 \% \mathrm{Cl}: 1.37-1.57, \mathrm{p}<0.001)$, prosocial behavior $(\mathrm{OR}=1.30 ; 95 \% \mathrm{Cl}: 1.19-1.41, \mathrm{p}<0.001)$, and total difficulties $(\mathrm{OR}=1.66$; $95 \% \mathrm{Cl}$ : 
$1.52-1.82, \mathrm{p}<0.001)$. Furthermore, higher $\mathrm{OA}$ was also found with stronger emotional symptoms (OR $=1.15 ; 95 \% \mathrm{Cl}: 1.09-1.28, \mathrm{p}<0.001)$, hyperactivity problems $(\mathrm{OR}=1.11 ; 95 \% \mathrm{Cl}: 1.03-1.20, \mathrm{p}<0.01)$, and prosocial behavior $(\mathrm{OR}=1.36 ; 95 \% \mathrm{Cl}: 1.26-1.47, \mathrm{p}<0.001)$.

Table 3 Correlation between ST and OA and emotional and behavioral health problems

\begin{tabular}{|c|c|c|c|}
\hline & & screen time(Ref: $\leq 2 h)$ & physical activity (Ref: $\geq 1 \mathrm{~h}$ ) \\
\hline \multirow[t]{3}{*}{ emotional symptoms } & normal(Ref) & & \\
\hline & borderline & $1.27(1.17,1.39)^{\star \star \star}$ & $1.05(0.98,1.14)$ \\
\hline & abnormal & $1.47(1.37,1.57)^{\star \star \star}$ & $1.06(1.01,1.13)^{\star}$ \\
\hline \multirow[t]{3}{*}{ conduct problems } & normal(Ref) & & \\
\hline & borderline & $1.34(1.28,1.44)^{\star \star \star}$ & $0.95(0.89,1.02)$ \\
\hline & abnormal & $1.63(1.52,1.75)^{\star \star \star}$ & $0.89(0.82,0.97)^{\star \star}$ \\
\hline \multirow[t]{3}{*}{ hyperactivity problems } & normal(Ref) & & \\
\hline & borderline & $1.35(1.24,1.47)^{\star \star \star}$ & $1.15(1.06,1.24)^{\star *}$ \\
\hline & abnormal & $1.18(1.09,1.28)^{\star \star \star}$ & $1.32(1.23,1.42)^{\star \star \star}$ \\
\hline \multirow[t]{3}{*}{ peer problems } & normal(Ref) & & \\
\hline & borderline & $1.08(1.01,1.16)^{\star}$ & $1.00(0.97,1.06)$ \\
\hline & abnormal & $1.26(1.19,1.34)^{\star \star \star}$ & $0.99(0.94,1.05)$ \\
\hline \multirow[t]{3}{*}{ prosocial behaviors } & normal(Ref) & & \\
\hline & borderline & $1.21(1.18,1.30)^{\star \star \star}$ & $1.19(1.12,1.27)^{\star \star \star}$ \\
\hline & abnormal & $1.30(1.19,1.41)^{\star \star \star}$ & $1.41(1.3,1.52)^{\star \star \star}$ \\
\hline \multirow[t]{3}{*}{ total difficulties } & normal(Ref) & & \\
\hline & borderline & $1.21(1.11,1.2)^{\star \star \star}$ & $1.05(0.94,1.21)$ \\
\hline & abnormal & $1.66(1.52,1.82)^{\star \star \star}$ & $1.02(0.94,1.11)$ \\
\hline
\end{tabular}

The model was controlled for sex, parents' education level, family economic level, academic record, and homeplace: ${ }^{*} p<0.05 ;{ }^{\star \star} p<0.01 ;{ }^{* \star \star} \mathrm{p}<0.001$.

\subsection{Study on emotional and behavioral health problems and additive interaction model between outdoor activity and screen time}

In Fig. 1, after adjusting confounders, we explored the influence of OA and ST synergy on emotional and behavioral health problems. Variables were categorized into four groups: high PA + low ST, high OA + high ST, low OA + low ST, and low OA + high ST. Emotional and behavioral health problems were categorized into three groups: normal, and abnormal. In comparison with high OA + low ST, adolescents who had high ST and low OA demonstrated higher EBHPs (emotional symptoms: $\mathrm{OR}=1.65,95 \% \mathrm{Cl} 1.49-1.83, \mathrm{p}<0.001$; conduct problems: $\mathrm{OR}=1.60,95 \% \mathrm{Cl} 1.37-1.87, \mathrm{p}<0.001 ;$ peer problems: OR $=1.58$, $95 \% \mathrm{Cl} 1.35-1.84, \mathrm{p}<0.001$; prosocial problems: $\mathrm{OR}=1.83,95 \% \mathrm{Cl} 1.60-2.08, \mathrm{p}<0.001$; hyperactivity problems: $\mathrm{OR}=1.79,95 \% \mathrm{Cl} 1.59-2.03, \mathrm{p}<0.001$; total difficulties: $\mathrm{OR}=1.88,95 \% \mathrm{Cl} 1.64-2.15, \mathrm{p}<0.001$ ). Additionally, we discuss high OA + high ST and low OA + low ST in terms of prosocial problems, and hyperactivity problems scores, since all two were risk factors for high OA + low ST at abnormal level. there was no correlation between low OA + low ST and abnormal scores, but high OA + high ST were correlated with abnormal scores in total difficulties (OR = 1.5, 95\% Cl: 1.34-1.68), emotional symptoms (OR = $1.30,95 \% \mathrm{Cl}: 1.20-1.42)$ and conduct problems $(\mathrm{OR}=1.51,95 \% \mathrm{Cl}: 1.34-1.68)$. Moreover, there were no association between high OA + high ST and low PA + low ST in abnormal peer problems $(\mathrm{OR}=1.12,95 \% \mathrm{Cl}: 0.99-1.28$ and $\mathrm{OR}=0.93,95 \% \mathrm{Cl}: 0.83-1.04)$.

In emotional and behavioral health problems and the additive interaction model between OA and ST, our results have shown that low OA and high ST are positively correlated with emotional symptoms, hyperactivity problems, peer problems, prosocial behaviors, and total difficulties. High OA and low ST were negatively related to emotional symptoms, hyperactivity problems, peer problems, prosocial behaviors, and total difficulties.

\section{Discussion}

This study investigated the associations between ST and OA and EBHPs in Chinese children and adolescents. After adjusting for confounding factors, ST and OA were found to have independent and additive interaction effects on EBHPs. There were gender differences in the distribution of EBHPs. Boys were more likely than girls to report conduct problems, hyperactivity problems, peer problems, and prosocial behavior. This result supports conclusions of previous studies [42-45]. Results were similar to other studies showing girls are more likely to have higher emotional symptoms [46,47].

With progress in science and technology, the use of electronic products and mobile phones has increased significantly. Some studies have proposed that more than half of students have high ST (>2 h/d) [48]. One study found that watching television, videos, or DVDs for three hours or more daily is associated with a 
small increase in conduct problems between ages 5 and 7 [22]. According to an American study, computer ST was correlated with SDQ scores [49]. Studies of younger-aged children demonstrated that higher ST is a risk factor for EBHPs [50]. Other studies have found a correlation between emotional or behavioral difficulties and spending more time on computers [51-53], as well as increased difficulty in disengaging from the computer [54]. This also reflects the influence of electronic devices on interpersonal communication. High ST can cause various maladaptive psychophysiological responses, such as arousal of the central nervous system, and can also adversely affect sleep patterns [55]. Adolescents with psychosocial difficulties may choose to use ST as a form of self-release. Another study explained the relationships between inactivity, ST, and psychosocial difficulties as bidirectional [56]. In addition, children who suffered from neurodevelopmental disorders had more difficulties disengaging from screen devices, which could exacerbate emotional/behavioral difficulties [57]. Similarly, our findings support the conclusion that high ST has adverse effects on the EBHPs of children and adolescents [58].

Our OA findings are consistent with other PA and OA studies [3,26, 59-60,]. The mechanism between PA and EBHPs attributed to PA may improve monoamines (norepinephrine and serotonin) by increasing neurotransmitter activity and increasing or moderately activating the limbic system and decreasing cortisol levels [61], indicating that PA can improve mental health outcomes for all children, in a similar way, PA and OA are supplement each other, adolescents who spending more time outside is associated with higher physical activity levels, which in turn increase the probability of improvement mental health [26]. OA can encourage opportunities for school connectedness and intra- and interpersonal development for young people, highlight the importance of fostering school connectedness and interpersonal communication in supporting healthy adolescent development [48,62-63], lower isolation and loneliness [64], and increase confidence and social skills $[65,66]$ to improve students' mental health. The special effect of outdoor activity has also been reported with some studies that be associated with positive mood and mental well-beings [62]. Beyond these, outdoor activity is also used as therapy, which is associated with decreased symptoms of ADHD [67]. Moreover, the effect of outdoor activity which is not only limited to the psychological status of the normal population, but also plays an important regulating role in diabetes patients [68]. Furthermore, compared with physical activity indoors, exercising in outdoor environments was associated with greater feelings of emotion and positive engagement, decreases in negative emotion and depression, and adverse psychological mood; one possible reason is participants reported greater enjoyment and satisfaction with outdoor activity and declared a greater intent to repeat the activity at a later date [69]. Therefore, it is imperative to promote outdoor activities for children and adolescents.

We found a remarkable additive interaction between high ST and OA on EBHPs. The additive interaction model analysis demonstrates that the combination of low OA and high ST are positively associated with concurrent total difficulties when compared with high PA and low ST after controlling for other confounders. In addition, high ST and insufficient OA interact to increase psychological problems. Also, in comparison with high OA and low ST, low OA and low ST and low OA and high ST were correlated with some scales. Some possible reasons were that high ST may displace their study and OA time, then further infect their physical and psychosocial health [70-72]. Meanwhile, each additional hour spent outdoors per day was associated with 7.0 more minutes of moderate- to- vigorous physical activity, 762 more steps, and 13 fewer minutes of sedentary time [29]. Extended exposure to screens limits opportunities for personal connectedness, problem-solving, and self-development, and promotes isolation, which can increase adolescents' vulnerability to adverse mental health outcomes [73]. Previous research demonstrates the interactive effects of insufficient PA and high ST on psychological difficulties in children and adolescents [32,74-76]. But there is no study about outdoor activity and screen time on mental health among children and adolescents. Adolescents in Dhaka City who had high recreational ST and were not meeting PA recommendations were more likely to suffer psychosocial difficulties [2]. The frequency of emotional and behavioral health problems and the potential long-term consequences make it an important research topic in relation to risk and protective factors and strongly implies a need to identify strategies to reduce this public health problem. Our study explores factors affecting EBHPs from the perspective of ST and OA, providing a theoretical basis for solving public health problems on children and adolescents.

Our study has the primary strength of having a large sample size. We distributed this survey through 6 streets and 14 schools, including elementary, junior high, and senior high schools. We also analysed several potential confounders. In this study, we adopted the interactive effect to explore the correlation between ST and OA and EBHPs, further demonstrating that we should pay close attention to those factors influencing the mental health of children and adolescents.

This research also has several limitations. First, this study is cross-sectional and could not determine causality or direction. Second, ST and OA were acquired through self-reporting, which may introduce a recall bias. Our further research has utilized objective measures such as accelerometers to assess OA and ST. Third, we could not obtain answers from absent students. Poor mood and behavioral health problem status may be more prevalent among frequently or longterm absent students. Therefore, the prevalence of mood health problems detected in this study is likely underestimated.

\section{Conclusion}

In this study, our results confirmed that high exposure to ST and OA increase the risk of EBHPs among Chinese children and adolescents. Overall, time spent outdoors was consistently associated with improved physical behaviors (i.e., more physical activity and less sedentary behavior) and fitness outcomes when compared with time spent indoors. Children with higher amounts of outdoor time engaged in higher amounts of physical activity and lower amounts of sedentary behavior than children who spend less time outdoors. The simultaneous associations of ST and OA on emotional symptoms, conduct problems, hyperactivity problems, prosocial problems, and total difficulties were stronger than those of ST or OA, individually.

\section{Abbreviations}

Screen Time: ST

Outdoor Activity: OA

Emotional and Behavioral Health Problems: EBHPs 
Strengths and Difficulties Questionnaire: SDQ

Attention Deficit Hyperactivity and Behavior Disorder: ADHD

Physical Activity: PA

\section{Declarations}

\section{Ethics approval and consent to participate}

The study was approved by the Ethics Committee of Anhui Medical University. All focus group participants provided signed informed consent prior to the start of the focus groups/.

\section{Consent for publication}

Not Applicable.

\section{Availability of data and materials}

The datasets that were generated analyzed for the current study are not publicly available as the author does not have permission to share the data.

\section{Competing interests}

The authors declare that they have no competing interests.

\section{Funding}

This research was funded by the National Public Welfare Industry Scientific Research Master (201202010). These institutions had no further role in the study design, the collection and analysis of data, the writing of the report, and the decision to submit the paper for publication.

\section{Authors' Contributions}

FBT conceptualized the study and developed the interview guide. YZ and XYW conduced the qualitative analysis and QLW conducted the quantitative analysis. YZ drafted the manuscript. RJW, QZ, TTL contributed significantly to the drafting and revising of the article. All Authors read, commented and approved the final manuscript.

\section{Acknowledgments}

We frankly thank all participants and the schools involved in the survey, as well as other staff members on the scene.

\section{References}

1 Hölling H, Kurth BM, Rothenberger A, Becker A, Schlack R. Assessing psychopathological problems of children and adolescents from 3 to 17 years in a nationwide representative sample: results of the German health interview and examination survey for children and adolescents (KiGGS). Eur Child Adolesc Psychiatry. 2008, 17, 34-41. https://doi.org/10.1007/s00787-008-1004-1

2 Kieling C, Baker-Henningham H, Belfer M, Conti G, Ertem I, Omigbodun O, Rohde LA, Srinath S, Ulkuer N, Rahman A. Child and adolescent mental health worldwide: evidence for action. Lancet. 2011, 378, 1515-1525. doi:10.1016/S0140-6736(11)60827-1

3 Khan A, Uddin R, Burton NW. Insufficient physical activity in combination with high screen time is associated with adolescents' psychosocial difficulties. Int Health. 2018, 10, 246-251. doi:10.1093/inthealth/ihy019

4 Zimmerman FJ, Christakis DA. Children's television viewing and cognitive outcomes-a longitudinal analysis of national data. Arch Pediatr Adolesc Med. 2005, 159, 619-625. doi:10.1001/archpedi.159.7.619

5 Cain N, Gradisar M. Electronic media use and sleep in school-aged children and adolescents: A review. Sleep Med. 2010, 11: 735-742. doi:10.1016/j.sleep.2010.02.006

6 Pagani LS, Fitzpatrick CMA, Barnett TA. Prospective associations between early childhood television exposure and academic, psychosocial, and physical well-being by middle childhood. Arch Pediatr Adolesc Med. 2010, 164: 425-431. doi:10.1001/archpediatrics.2010.50

7 Mistry K, Minkovitz C, Strobino D, Borzekowski-Dina LG. Children's television exposure and behavioral and social outcomes at 5.5 years: does timing of exposure matter? Pediatrics. 2007, 120, 762-769. doi:10.1542/peds.2006-3573

8 Singer Ml, Slovak K, Frierson T, York P. Viewing preferences, symptoms of psychological trauma, and violent behaviors among children who watch television. J Am Acad Child Adolesc Psychiatry. 1998, 37, 1041-1048. doi:10.1097/00004583-199810000-00014 
9 Singer MI, Flannery DJ, Guo SY, Miller D, Leibbrandt S. Exposure to violence, parental monitoring, and television viewing as contributors to children's psychological trauma. J Community Psychol. 2004, 32, 489-504. doi:10.1542/peds.104.4.878

10 Bickham, D.S.; Rich, M. Is television viewing associated with social isolation? Roles of exposure time, viewing context, and violent content. Arch Pediatr Adolesc Med. 2006, 160, 387-392. doi:10.1001/archpedi.160.4.387

11 Cheng, S.; Maeda, T.; Yoichi, S.; Yamagata, Z.; Tomiwa, K. Japan Children's Study Group., Early television exposure and children's behavioral and social outcomes at age 30 months. J Epidemiol. 2010, 20, S482-S489. doi:10.2188/jea.je20090179

12 Christakis, D.A., Zimmerman, F.J., DiGiuseppe, D.L., McCarty, C.A., Early television exposure and subsequent attentional problems in children. Pediatrics 2004, 113, 708-713. doi:10.1542/peds.113.4.708

13 Swing, E.L., Gentile, D.A., Anderson, C.A., Walsh, D.A., Television and video game exposure and the development of attention problems. Pediatrics 2010, 126, 214-221. doi:10.1542/peds.2009-1508

14 Lissak, G. Adverse physiological and psychological effects of screen time on children and adolescents: literature review and case study. Environ. Res. 2018, 164, 149-157. doi:10.1016/j.envres.2018.01.015

15 Maras, D., Flament, M.F., Murray, M., Buchholz, A., Henderson, K.A., Obeid, N., Goldfield, G.S. Screen time is associated with depression and anxiety in Canadian youth. Prev. Med. 2015, 73, 133-138. doi:10.1016/j.ypmed.2015.01.029

16 Twenge, J.M., Campbell, W.K. Associations between screen time and lower psychological well-being among children and adolescents: evidence from a population based study. Prev. Med. Rep. 2018, 12, 271-283. doi:10.1016/j.pmedr.2018.10.003

17 Vandewater, E.A., Bickham, D.S., Lee, J.H., Time well spent? Relating television use to children's free-time activities. Pediatrics 2006, 117, e181-e191. doi: 10.1542/peds.2005-0812

18 Anderson, C.A., Gentile, D.A., Dill, K.E. Prosocial, antisocial, and other effects of recreational video games. In D. G. Singer \& J. L. Singer (Eds.), Handbook of children and the media. 2012, 249-272.

19 Colwell, J. Needs met through computer game play among adolescents. Pers Individual Differences. 2007, 43, 2072-2082. doi: 10.1016/j.paid.2007.06.021

20 Gentile, DA., Choo, H., Liau, A., Sim, T., Li, DD., Fung, D., Khoo, A. Pathological video game use among youths: a two-year longitudinal study. Pediatrics 2011, 127, e319-e329. doi:10.1542/peds.2010-1353

21 Parkes, A., Sweeting, H., Wight, D., Henderson, M. Do television and electronic games predict children's psychosocial adjustment? Longitudinal research using the UK Millennium Cohort Study. Arch Dis Child. 2013. 98, 341-348. doi:10.1136/archdischild-2011-301508

22 Sund, A.M., Larsson, B., Wichstrøm, L. Role of physical and sedentary activities in the development of depressive symptoms in early adolescence. Soc Psychiatry Psychiatr Epidemiol, 2011, 46, 431-441. doi:10.1007/s00127-010-0208-0

23 White, K., Kendrick, T., Yardley, L. Change in self-esteem, self-efficacy and the mood dimensions of depression as potential mediators of the physical activity and depression relationship: exploring the temporal relation of change. Ment Health Phys Act. 2009, 2, 44-52. doi: 10.1016/j.mhpa.2009.03.001

24 Hallal, PC., Andersen, LB., Bull, FC., Guthold, R., Haskell, W., Ekelun, U. Global physical activity levels: surveillance progress, pitfalls, and prospects. Lancet, 2012, 380, 247-257. doi:10.1016/S0140-6736(12)60646-1

25 Nicola J., Gareth T.J., Anne M.H., Debbie A.L., Gary J.M., Glyn L. Physical activity and emotional problems amongst adolescents: A longitudinal study. Soc Psychiatry Psychiatr Epidemiol. 2008, 43, 765-772. doi: 10.1007/s00127-008-0362-9

26 Bélanger M, Gallant F, Doré I, O'Loughlin JL, Sylvestre MP, Abi Nader P, Larouche R, Gunnell K, Sabiston CM. Physical activity mediates the relationship between outdoor time and mental health. Prev Med Rep. 2019, 16, 101006. Published 2019 Oct 21. doi:10.1016/j.pmedr.2019.101006

27 Song C, Ikei H, Miyazaki Y. Physiological Effects of Nature Therapy: A Review of the Research in Japan. Int J Environ Res Public Health. $2016,13,781$. Published 2016 Aug 3. doi:10.3390/ijerph13080781

28 Beyer K.M.M., Szabo A., Nattinger A.B. Time spent outdoors, depressive symptoms, and variation by race and ethnicity. Am. J. Prev. Med. 2016, 51, 281290. doi:10.1016/j.amepre.2016.05.004

29 Larouche R., Garriguet D., Gunnell K.E., Goldfield G.S., Tremblay M.S. Outdoor time, physical activity, sedentary time, and health indicators at ages 7 to 14 : 2012/2013 Canadian Health Measures Survey. Heal. Reports. 2016, 27, I3-13

30 Doré I., O'Loughlin J.L., Beauchamp G., Martineau M., Fournier L. Volume and social context of physical activity in association with mental health, anxiety and depression among youth. Prev. Med. (Baltim) 2016, 91, 344-350. doi:10.1016/j.ypmed.2016.09.006

31 Piccininni C, Michaelson V, Janssen I, Pickett W. Outdoor play and nature connectedness as potential correlates of internalized mental health symptoms among Canadian adolescents. Prev Med. 2018, 112, 168-175. doi:10.1016/j.ypmed.2018.04.020.

Page 9/12 
32 Cao, H., Qian, Q.W., Weng, T.T., Yuan, C.J., Sun, Y., Wang, H., Tao, F.B. Screen time, physical activity and mental health among urban adolescents in China. Prev Med. 2011, 53, 316-320. doi:10.1016/j.ypmed.2011.09.002

33 Janssen I, Leblanc AG. Systematic review of the health benefits of physical activity and fitness in school-aged children and youth. Int J Behav Nutr Phys Act. 2010, 7, 40. doi:10.1186/1479-5868-7-40

34 Suchert, V., Hanewinkel, R., Isensee, B. Sedentary behavior and indicators of mental health in school-aged children and adolescents: a systematic review. Prev Med. 2015, 76, 48-57. doi:10.1016/j.ypmed.2015.03.026

35 Bassett, D.R., John. D., Conger, S.A, Fitzhugh EC, Coe DP. Trends in physical activity and sedentary behaviors of United States youth. J Phys Act Health. 2015, 12, 1102-1111. doi:10.1123/jpah.2014-0050

36 Hofferth SL. Changes in American children's time-1997 to 2003. Electr Int J Time Use Res. 2009, 6,26-47. doi: 10.13085/elJTUR.6.1.26-47

37 Tammelin, T., Ekelund, U., Remes, J., Nayha, S. Physical activity and sedentary behaviors among Finnish youth. Med. Sci. Sports Exerc. 2007, 39: 10671074. doi:10.1249/mss.0b13e318058a603

38 Tremblay, M.S., LeBlanc, A.G., Janssen, I., Kho, M.E., Hicks, A., Murumets, K., Colley, R.C., Duggan, M. Canadian sedentary behavior guidelines for children and youth. Appl. Physiol. Nutr. Metab. 2011a, 36: 59-64. doi:10.1139/H11-012

39 Goodman R., Renfrew D., Mullick M. Predicting type of psychiatric disorder from strengths and difficulties questionnaire (SDQ) scores in child mental health clinics in London and Dhaka. Eur. Child. Adolesc. Psychiatry 2000, 9, 129-134. doi:10.1007/s007870050008

40 Gao, X., Shi, W., Zhai, Y., He, L., Shi, X. Results of the parent-rated Strengths and Difficulties Questionnaire in 22,108 primary school students from 8 provinces of China. Shanghai Arch Psychiatry. 2013, 25(6): 364-374. doi:10.3969/j.issn.1002-0829.2013.06.005

41 Andersson, T., Alfredsson, L., Källberg, H., Zdravkovic, S., Ahlbom, A. Calculating measures of biological interaction. Eur J Epidemiol. 2005, 20 : 515-579. doi: $10.1007 /$ s10654-005-7835-x

$42 \mathrm{Du}$, Y., Kou, J., Coghill, D. The validity, reliability and normative scores of the parent, teacher and self report versions of the Strengths and Difficulties Questionnaire in China. Child Adolesc Psychiatry Ment Health 2008, 2, 8. doi:10.1186/1753-2000-2-8

43 Idris, IB., Barlow, J., Dolan, A. A longitudinal study of emotional and behavioral problems among Malaysian school children. Ann. Glob. Health. 2019, 85, 30. doi:10.5334/aogh.2336

44 Shibata, Y., Okada, K., Fukumoto, R., Nomura, K. Psychometric properties of the parent and teacher forms of the Japanese version of the strengths and difficulties questionnaire. Brain Dev. 2015, 37, 501-507. doi:10.1016/j.braindev.2014.08.001

45 Shojaei, T., Wazana, A., Pitrou, I., Kovess, V. The strengths and difficulties questionnaire: validation study in French school-aged children and cross-cultural comparisons. Soc Psychiat Epidemio/ 2009, 44, 740-747. doi:10.1007/s00127-008-0489-8

46 Giannakopoulos, G., Tzavara, C., Dimitrakaki, C., Kolaitis, G., Rotsika, V., Tountas, Y. The factor structure of the strengths and difficulties questionnaire (SDQ) in Greek adolescents. Ann. Gen. Psychiatry 2009. 8, 20. doi:10.1186/1744-859X-8-20

47 Muris, P., Meesters, C., van den Berg, F. The strengths and difficulties questionnaire (SDQ) - Further evidence for its reliability and validity in a community sample of Dutch children and adolescents. Eur. Child Adolesc. Psychiatry 2003, 12, 1-8. doi:10.1007/s00787-003-0298-2

48 Trinh, L., Wong, B., Faulkner, G.E. The independent and interactive associations of screen time and physical activity on mental health, school connectedness and academic achievement among a population-based sample of youth. J. Can. Acad. Child Adolesc. Psychiatry 2015. 24, 17-24. PMID: 26336376

49 Segev, A., Mimouni-Bloch, A., Ross, S., Silman, Z., Maoz, H., Bloch, Y. Evaluating Computer Screen Time and Its Possible Link to Psychopathology in the Context of Age: A Cross-Sectional Study of Parents and Children. PLoS ONE. 2015, 10, e0140542. doi: 10.1371/journal.pone.0140542

$50 \mathrm{Wu}, \mathrm{X}$., Tao, S., Rutayisire, E., Chen, Y., Huang, K., Tao, F. The relationship between screen time, nighttime sleep duration, and behavioral problems in preschool children in China. Eur. Child Adolesc. Psychiatry 2017, 26, 541-548. doi:10.1007/s00787-016-0912-8

51 Przybylski, A.K. Electronic gaming and psychosocial adjustment. Pediatrics. 2014, 134, e716-e722. doi: 10.1542/peds.2013-4021

52 Richards, R., McGee, R., Williams, S.M., Welch, D., Hancox, R.J. Adolescent screen time and attachment to parents and peers. Arch Pediatr Adolesc Med. 2010, 164, 258-262. doi:10.1001/archpediatrics.2009.280

53 Strasburger, V.C., Jordan, A.B., Donnerstein, E. Health effects of media on children and adolescents. Pediatrics. 2010, 125, 756-767. doi: 10.1542/peds.2009-2563

54 Bioulac, S., Arfi, L., Bouvard, M.P. Attention deficit/hyperactivity disorder and video games: a comparative study of hyperactive and control children. Eur Psychiatry. 2008, 23, 134-141. doi:10.1016/j.eurpsy.2007.11.002 
55 Wang, X., Perry, A. Metabolic and physiologic responses to video game play in 7- to 10-year-old boys. Arch Pediatr Adolesc Med. 2006, $160,411-415$. doi:10.1001/archpedi.160.4.411

56 Kremer, P., Elshaug, C., Leslie, E., Toumbourou, J.W., Patton, G.C., Williams, J. Physical activity, leisure-time screen use and depression among children and young adolescents. J Sci Med Sport 2014, 17, 183-187. doi:10.1016/j.jsams.2013.03.012

57 Lin, J.Y. , Magiati, I., Chiong, SHR., Swati, S., Natasha, R., Isabel, H-X.N., Falk, M-R., Wong, C.M. The Relationship Among Screen Use, Sleep, and Emotional/ Behavioral Difficulties in Preschool Children with Neurodevelopmental Disorders. J Dev Behav Pediatr 2019, 40, 519-529. doi:10.1097/DBP.0000000000000683

58 Hartman, E., Ketelaar, D., Lu, CC., Corpeleijn, E. Objectively measured physical activity and psychosocial functioning in young children: The GECKO Drenthe cohort. Journal of Sports Sciences 2019, 37, 2198-2204. doi:10.1080/02640414.2019.1626070

59 Ahn, S., Fedewa, A.L. A meta-analysis of the relationship between children's physical activity and mental health. Journal of Pediatric Psychology, 2011, 36, 385-397. doi:10.1093/jpepsy/jsq107

60 Knell, G., Durand, C.P., Kohl, H.W., Wu, IHC, Pettee, G.K. Prevalence and Likelihood of Meeting Sleep, Physical Activity, and Screen-Time Guidelines Among US Youth. JAMA Pediatr. 2019. 173, 387-389. doi:10.1001/jamapediatrics.2018.4847

61 Nabkasorn, C., Miyai, N., Sootmongkol, A., Junprasert, S., Yamamoto, H., Arita, M., Miyashita, K. Effects of physical exercise on depression, neuroendocrine stress hormones and physiological fitness in adolescent females with depressive symptoms. Eur J Public Health. 2006, 16, 179-184.

doi:10.1093/eurpub/cki159

62 Eigenschenk B, Thomann A, McClure M, Davies L, Gregory M, Dettweiler U, Inglés E. Benefits of Outdoor Sports for Society. A Systematic Literature Review and Reflections on Evidence. Int J Environ Res Public Health. 2019, 15, 16(6):937. doi: 10.3390/ijerph16060937.

63 Weatherson, K.A., O'Neill, M., Lau, E.Y., Qian, W., Leatherdale, S.T., Faulkner, Guy E.J. The Protective Effects of School Connectedness on Substance Use and Physical Activity. J Adolesc Health. 2018, 63, 724-731. doi:10.1016/j.jadohealth.2018.07.002

64 Schrempft, S., Jackowska, M., Hamer, M., Steptoe A. Associations between social isolation, loneliness, and objective physical activity in older men and women. BMC Public Health 2019, 19, 74. doi:10.1186/s12889-019-6424-y

65 Guerrero, MD., Hoffmann, MD., Munroe-Chandler, KJ. Children's Active Play Imagery and Its Association with Personal and Social Skills and SelfConfidence. J Imag. Res. Sport Phys. Act. 2016, 11, 47-57.

66 McFadden, T., Fortier, M., Sweet, S.N., Tomasoned, J.R., McGinn, R., Levac, B.M. Canadian medical students' perceived motivation, confidence and frequency recommending physical activity. Preventive Medicine Reports 2019, 15, 100898. doi: 10.1016/j.pmedr.2019.100898

67 Vives Vilarroig J., Ruiz Bernardo M.P. Programa asistido con caballos para la atención psicopedagógica de un adolescente contda-h. Quad. Digit. Rev. De Nuevas Tecnol. Y Soc. 2017, 84, 142-155

68 Fraser M, Polson R, Munoz SA, MacRury S. Psychological effects of outdoor activity in type 2 diabetes: a review. Health Promot Int. 2020, $35,841-851$. doi:10.1093/heapro/daz064

69 Thompson Coon J, Boddy K, Stein K, Whear R, Barton J, Depledge MH. Does participating in physical activity in outdoor natural environments have a greater effect on physical and mental wellbeing than physical activity indoors? A systematic review. Environ Sci Technol. 2011, 45, 1761-1772.

doi:10.1021/es102947t

70 Chaput, J.P., Saunders, T.J., Mathieu, M.Ė., Henderson, M., Tremblay, M.S., O'Loughlin, J., Tremblay, A. Combined associations between moderate to vigorous physical activity and sedentary behavior with cardiometabolic risk factors in children. Appl Physiol Nutr Metab. 2015, 38, 477-483.

doi:10.1139/apnm-2012-0382

71 Janssen I. Estimating Whether Replacing Time in Active Outdoor Play and Sedentary Video Games With Active Video Games Influences Youth's Mental Health. J Adolesc Health. 2016, 59(5):517-522. doi:10.1016/j.jadohealth.2016.07.007

72 Tremblay, M.S., LeBlanc, A.G., Kho, M.E., Saunders, T.J., Larouche, R., Colley, R.C., Goldfield, G., Gorber, S.C. Systematic review of sedentary behavior and health indicators in school-aged children and youth. Int. J. Behav. Nutr. Phys. 2011b, 8, 98. doi:10.1186/1479-5868-8-98

73 Marshall, S.J., Biddle, S.J., Gorely, T. , Murdey, I., Relationships between media use, body fatness and physical activity in children and youth: a metaanalysis. Int J Obes Relat Metab Disord 2004, 28, 1238-1246. doi:10.1038/sj.ijo.0802706

74 Hamer, M., Stamatakis, E., Mishra, G. Psychological distress, television viewing, and physical activity in children aged 4 to 12 years. Pediatrics 2009, 123 , 1263-1268.

doi: 10.1542/peds.2008-1523 
75 Matin, N., Kelishadi, R., Heshmat, R., Motamed-Gorji, N., Djalalinia, S., Motlagh, M.E., Ardalan, G., Arefirad, T., Mohammadi, R. Joint association of screen time and physical activity on self-rated health and life satisfaction in children and adolescents: the CASPIAN-IV study. Int Health. 2017, 9, 58-68. doi:10.1093/inthealth/ihw044

76 Ussher, M.H., Owen C.G., Cook D.G., Whincup P.H. The relationship between physical activity, sedentary behavior and psychological well-being among adolescents. Soc. Psychiatry Psychiatr. Epidemiol. 2007, 42, 851--856. doi: 10.1007/s00127-007-0232-x.

\section{Figures}

A

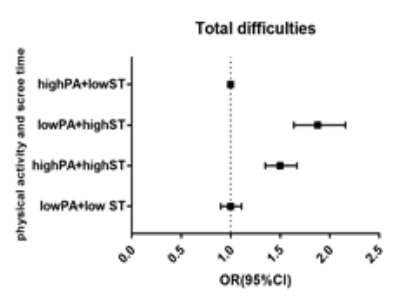

$\mathrm{C}$

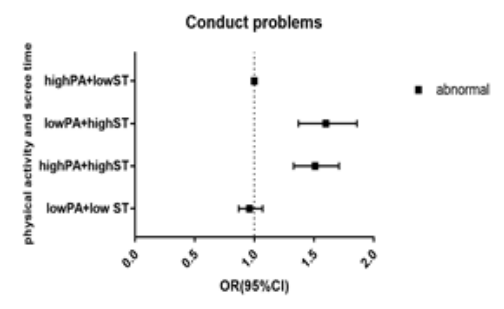

$\mathrm{E}$

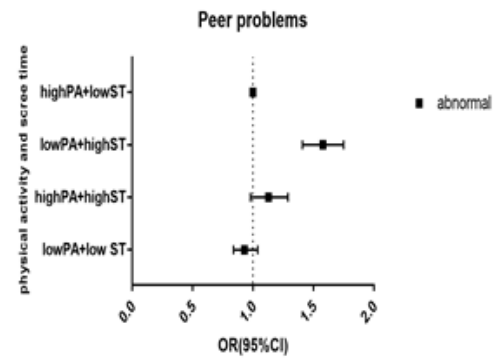

B
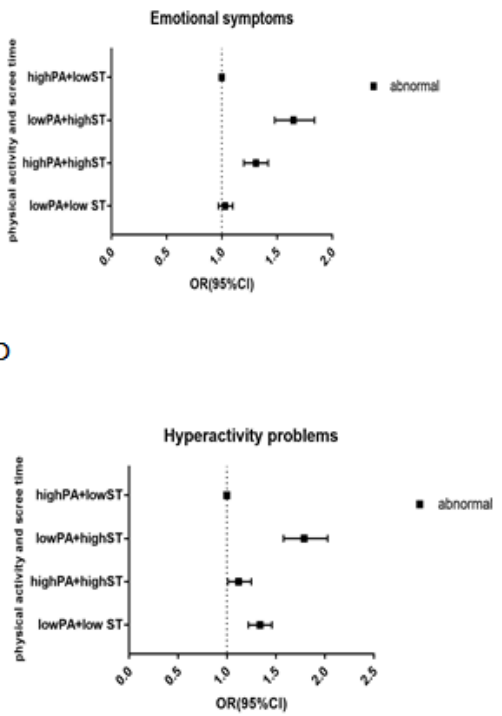

$\mathrm{F}$

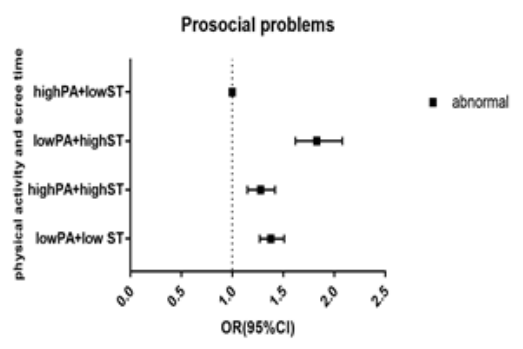

\section{Figure 1}

The OR value of emotional and behavioral health problems and interactive model of PA and ST (A: interaction between OA and ST on total difficulties; B: interaction between OA and ST on emotional symptoms; C: interaction between OA and ST on conduct problems; D: interaction between OA and ST on hyperactivity problems; E: interaction between OA and ST on peer problems; F: interaction between OA and ST on prosocial behaviors) 